\title{
An open - source Learning Management System (ASDL) using ICT for High Schools
}

\author{
S. Manitsaris \\ A. Perdos \\ S. Pavlidis \\ Ph.D. Student \\ Ph.D. Student \\ Teacher \\ Department of Applied Informatics, UOM \\ sotiris@uom.gr_perdos@uom.gr_sapavlidis@yahoo.gr
}

\begin{abstract}
This paper presents the specifications of an opensource Learning Management System using ICT, which was implemented on a Greek High school. This effort began because of our interest to see the impact of the use of Multimedia and Internet resources having elearning content, in a classroom. Greece lags far behind in use of Internet towards other European Countries. This paper also presents how pupils evaluated the use of this innovative pedagogical framework. Our research was extended to the new role that teachers called to adapt in teaching
\end{abstract}

\section{Introduction}

Personal use of Internet increases significantly in Europe even though the level of progress varies among the member countries (42\% in 2000 towards $53 \%$ in 2003). Greece lags far behind in use of Internet and in infrastructure. Only one to five Greek people used Internet in 2004. 55\% were students and Lyceum pupils towards the $85 \%$ of E.U other countries. A significant detail is that $40 \%$ of Greeks users search in Internet for educational purposes [1],[2].

$66 \%$ of Greeks who have Internet access use low bandwidth connections (PSTN) and only $1 \%$ have high bandwidth connection (ADSL) towards the 13\% European average percentage. $50 \%$ of Greek users access internet from their home, $25 \%$ from school or university, and 20\% from Cyber Café. Internet access from Cafés holds the biggest percentage in Europe.

Anyone can understand that even though Greece lacks Internet infrastructure, there is a great willing form students and pupils to use internet for educational purposes. Greece has the biggest access percentage from schools and universities in comparison to other European countries.
Computers can play significant role in the educational process as they bring important changes to the traditional way of teaching, with the use of multimedia and internet applications.

European and Greek experience shows that it is not very easy to apply ICT - based educational methods. There are many factors that contribute to this such as

- Infrastructure hardware

- Educational software

- Teachers' education

- National central planning

All the above difficulties create the need to put all the individual efforts of teachers under a single platform, which in no case substitutes the school and the traditional role of teacher. It is the use of the tool that will transform the educational process and not the tool itself [3].

\section{Characteristics of the Educational Platform}

Taking under consideration the situation described above, it is cleared that there is a need to create a platform for distance education, adapted in following characteristics:

Sharing of knowledge

It is important to publish educational material as well as to access it, not only during the tutorials (synchronous education) but also during the study and preparation (asynchronous education).

Interaction between teachers and pupils

Another requirement is to extent communication between teachers and pupils beyond the limits of the school building. In this way pupils sense the presence of teacher, even when they study.

Administration of courses - classes - schools

For best administration, the platform must satisfy some basic organizational operations such as the 
bulletin board, workgroups, homeworks and the exemplarily resolved exercises.

Intensification of wish to access the knowledge

The most important success factor for distance education, regarding pupils of High school or Lyceum, is the satisfaction that they feel from this process.

Self-assessment of students

On- line tests such as multiple choice tests

Personalization for each student and professor

The educational software should be adapted in the demands of teachers. As far as pupils are concerned they should be able to evaluate his knowledge through escalated difficulty tests

A lot of new ideas that use the significance of proximity, concerning ICT, make their appearance, "proximity digital spaces", "proximity distance education" etc. The ICT can decrease distance of exchange of all kind of information. Before the integration of ICT in the educational process, the proximity had powerful bonds with geographic distance, size absolutely measurable. We easily can conclude the differentiation from the direction of geographic distance to that of points of presence in the World Wide Web, and the hyperlinks that connect them. In other words, even if the schoolteacher and the pupil are not found in the same place, they feel very close to each other. Consequently for "digital spaces" or better for "digital worlds", the idea of geographic distance does not exist any more if there is a common objective or framework [4], [5].

\section{ASDL Asynchronous and Synchronous Distance Learning}

ASDL is a platform that integrates the functionality of a dynamic database and the ability to store and project educational multimedia information. Moreover it is not required technical knowledge of Internet services, in order to publish and manage data as it offers remote management only by using an Internet browser.

Links between the platform and the educational process are multi-dimensional based on the need of teachers and pupils to communicate in a virtual classroom [6].

ASDL, which is an extension of an existing system named DOKEOS, meets synchronous communication requirements such as videoconferencing, streaming video and SCORM (Sharable Content Object Reference Model) lessons [7] in Greek language. It is implemented by Multimedia and Graphics Lab of the Department of Applied Informatics of University of Macedonia, Greece [8], [9]. After an extended research, we found that familiar platforms do exist in other universities and schools but they do not meet all the specifications of ASDL. Therefore we examined if this platform could be applied in High Schools and Lyceums and tried to evaluate its use.

\section{Briefly ASDL:}

- Supports storage and projection of educational multimedia files. In addition SCORM lessons can be supported in order to achieve reusability, accessibility and interoperability of the content only by using any internet browser.

- Offers distance administration as everything can be done only by using an internet browser. In this way there is no demand for users to possess technical knowledge as well as for the administrator to be physically presented.

- Supports different kinds of users in order to provide personalization, protect the files and the parameters of the platform and make the administration easier.

- Supports videoconferencing and streaming video and as a consequence it gives the feasibility for synchronous education. Therefore it cancels all the geographical limits that do exist in Greece.

All these features show that ASDL create proximity links between teachers and pupils or even better between pupils and the lesson. Therefore a virtual educational community is created.

\section{The application of ASDL in education}

According to statistics concerning the use of Internet and the technical infrastructure in Greece, the ASDL exceeds all the mentioned difficulties because:

1 It suppresses the distance as an obstacle of communication because it is based on the technology of Internet

2 It offers easy access to knowledge because it is just a web page in the Internet and there is no need for expensive equipment usually required by ICT. Therefore the segregation in privileged and not students is abolished.

3 It exceeds the problem of low connection speeds in the Internet. The solution that was adopted, concerns creation of pages that do not require significant transferring times from servers to clients. Moreover the publication of educational material is achieved with very low speeds of $33,6 \mathrm{Kbps}$.

4 The platform is based on a simple installation in a central computer, unique for a lot of schools. Thus, 
the user of ASDL needs only an operating system, an internet browser and office applications.

5 The system can function even with computers with low resources.

6 The high economic demands often prohibit the financing and the creation of such applications in schools. The ASDL is an open source platform.

7 ASDL resolves the problem of distance when it concerns Greek islands and inaccessible mountainous villages. The world is flat as Bill Gates said.

8 The level of required knowledge concerning the use of ASDL is as minimal as possible. Greek teachers have been trained in use of computers during the seminars organized by Information Society. Pupils have just to recall the knowledge that they acquire from the course of Informatics in the High school

\section{ASDL and Evaluation}

Our opinion about the role of the schoolteacher and the way that a course is implemented, is definitely influenced by our perceptions and beliefs and the relative research that we have conducted [10], [11], [12], [13], [14]. In order to obtain a more integrated perception, questionnaires were given to pupils. The questionnaires consisted of 38 questions divided in 9 sections depending on the use, the operability and the undertaking of whole process. Some indicative questions that show the opinion of pupils about the use of ASDL, are now presented.

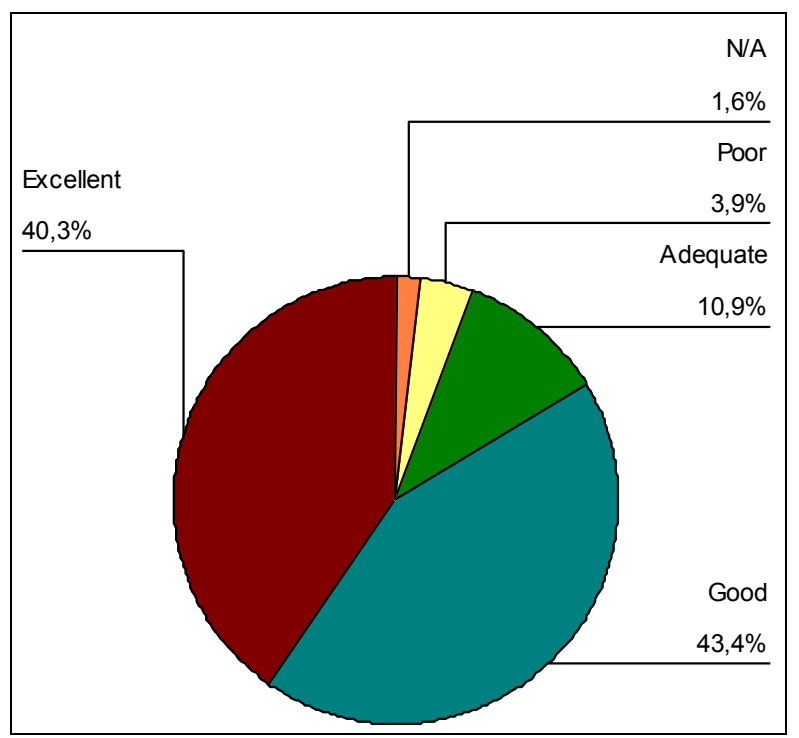

Figure 1. What is your opinion about ASDL?

The first question is about how pupils estimate ASDL. It is obvious from the following graph that a great percentage of pupils strongly accepted the concept of ASDL.

The following graph shows if ASDL helped pupils in case of absence.

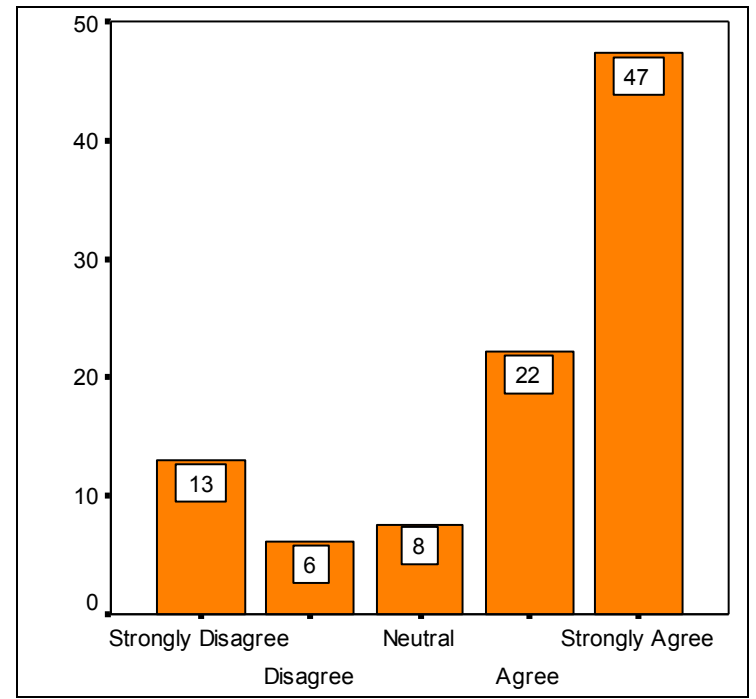

Figure 2. Does ASDL help in case of absence?

Although it is obvious that ASDL helps pupils to obtain the same level of knowledge either in case of absence or not, there is a significant percentage of pupils that consider ASDL did not actually helped them. An explanation for this, lies in the fact that some pupils did not have internet access from their home. There is also the possibility that some pupils are used to the traditional way of teaching and they cannot adapt themselves to ICT based training.

Another indicative question that shows how ASDL brings new standards in education is shown in Figure 3

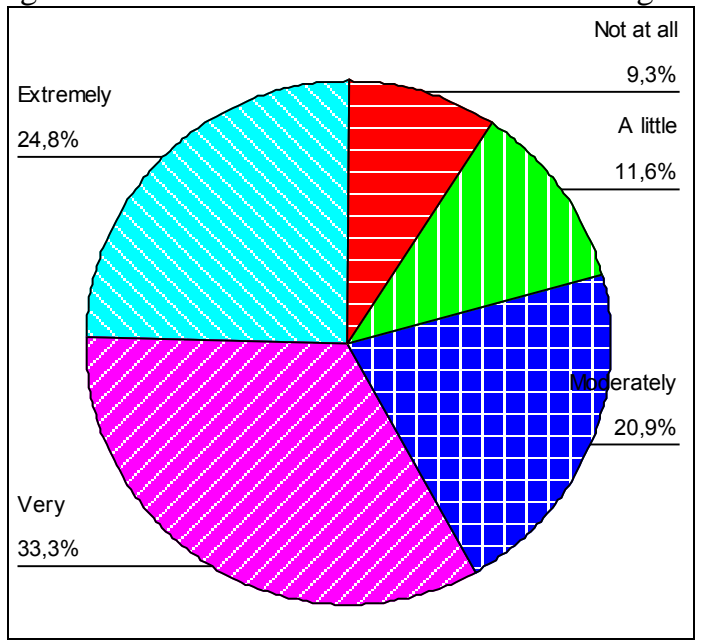

Figure 3. Does ASDL give a motive for study?

The fact that pupils find a motive to study more is not only proved by the above diagram but also from the grades they achieved. This fact was observed by us 
during the teaching process and was confirmed by the pupils through the questionnaire.

\section{Conclusion and Future Work}

After the analysis of the questionnaire and the experience that we obtained through the teaching process we came in the following conclusions

1 If a pupil loses a tutorial because of case of illness or participation in school activities, he/she has the ability to have access to the presentations, the examples and all the teaching material. In this way all students obtain the same level of knowledge either they attend the classroom or not.

2. The pupils have better assimilation of the course concepts in comparison with to the ones of previous years. In this, contributes the fact that they have the chance to do exercises and tests from their home and evaluate their knowledge.

3. The pupils recognize that computers do not exist only for playing games but also as a mean to gain knowledge. Since they are familiar with ICT, they will probably correspond very easily later, in the requirements of their academic studies.

For more than 6 months ASDL supports two courses of secondary education that have very high acceptance from pupils. This encourages us to create courses based on SCORM lessons, which will be available next school year. We also intend to create videos lectures and use ASDL's videoconference feature more, in order to share knowledge in various ways.

\section{References}

[1] Internet and the public at large, FlassEB no135- report, p. 25 , fig 4 a, accessed on $3 / 2 / 2006$, http://europa.eu.int/comm/public_opinion/flash/fl125_en.pdf [2] The digital divide in Europe, (2005), Eurostat News Release 143/2005, accessed on 3/2/2006

http://epp.eurostat.cec.eu.int/pls/portal/docs/PAGE/PGP_PR D_CAT_PREREL/PGE_CAT_PREREL_YEAR_2005/PGE _CAT_PREREL_YEAR_2005_MONTH_11/4-10112005EN-AP.PDF

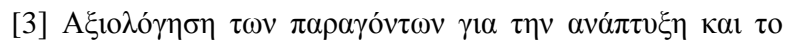

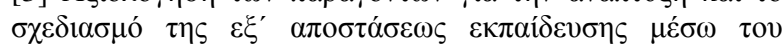

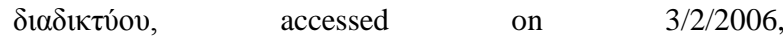

http://www.eap.gr/news/EXAGGELIA_SYNEDRIOU/syned $\mathrm{rio} / \mathrm{html} / \mathrm{sect} 5 / 85 . \mathrm{htm}$

[4] Les conditions de réussite du e-learning et le travail collaboratif dans les collectivités locales, accessed on 3/2/2006, http://www.renupi.org/IMG/pdf/e-learning_travailcollaboratif-2.pdf

[5] Proximité et Société de l'Information, accessed on $3 / 2 / 2006$

http://www.renupi.org/IMG/pdf/proximite_societe_de_1_info rmation.pdf

[6] FLYNN, J., "Cooperative learning and Gagne's events of instruction: a syncretice view", Educational Technology, October (1992), p. 53-60

[7] KAZI S., "A conceptual framework for web-based intelligent learning environment using scorm", advanced learning technologies, (2004), p12-15

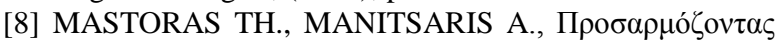

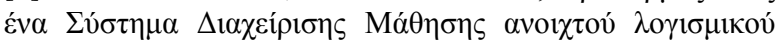

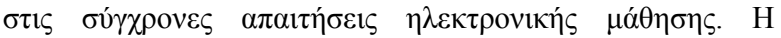

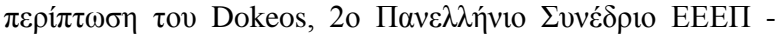

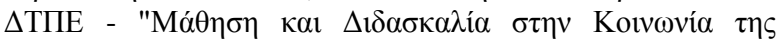

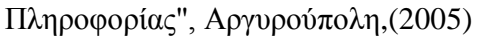

[9] MASTORAS TH., MANITSARIS A., MAYRIDIS I.H

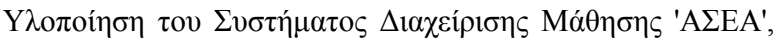

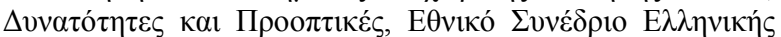

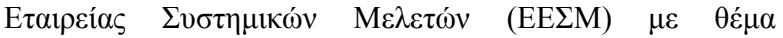

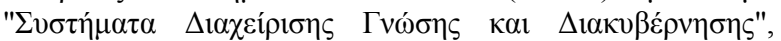

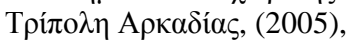

[10] SCHLECHTER, T. "The relative instructional efficiency of small group computer-based training", Journal of Education Computing Research, Vol. 6, No. 3, (1990), p329341

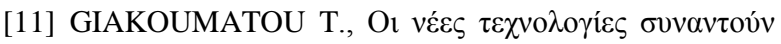

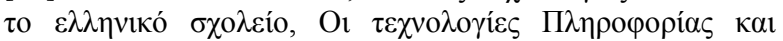

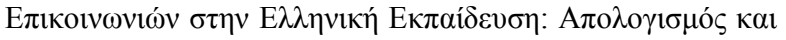

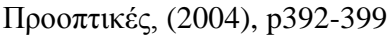

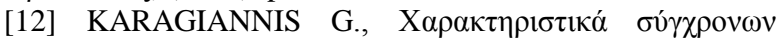

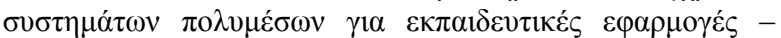

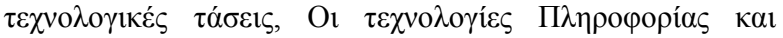

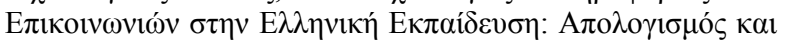

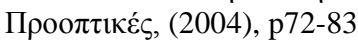

[13] PAVLIDIS S., PERDOS A., MANITSARIS S.

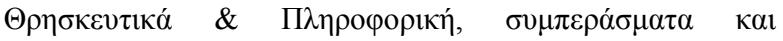
$\alpha \xi$ เo

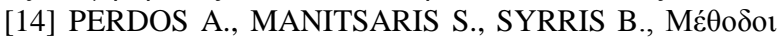

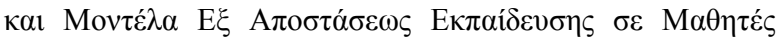

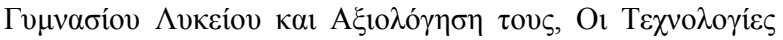

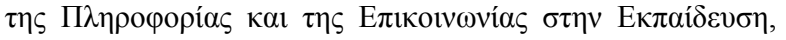
AӨท́va, (2004), p579-584 